\title{
Knowledge, attitudes and practice of general practitioners towards complementary and alternative medicine in Doha, Qatar
}

\author{
I.A.M.S. Al Shaar, M.F.S. Ismail, ${ }^{1,2}$ W.A.A.A. Yousuf and R.E. Salama ${ }^{1,3}$
}

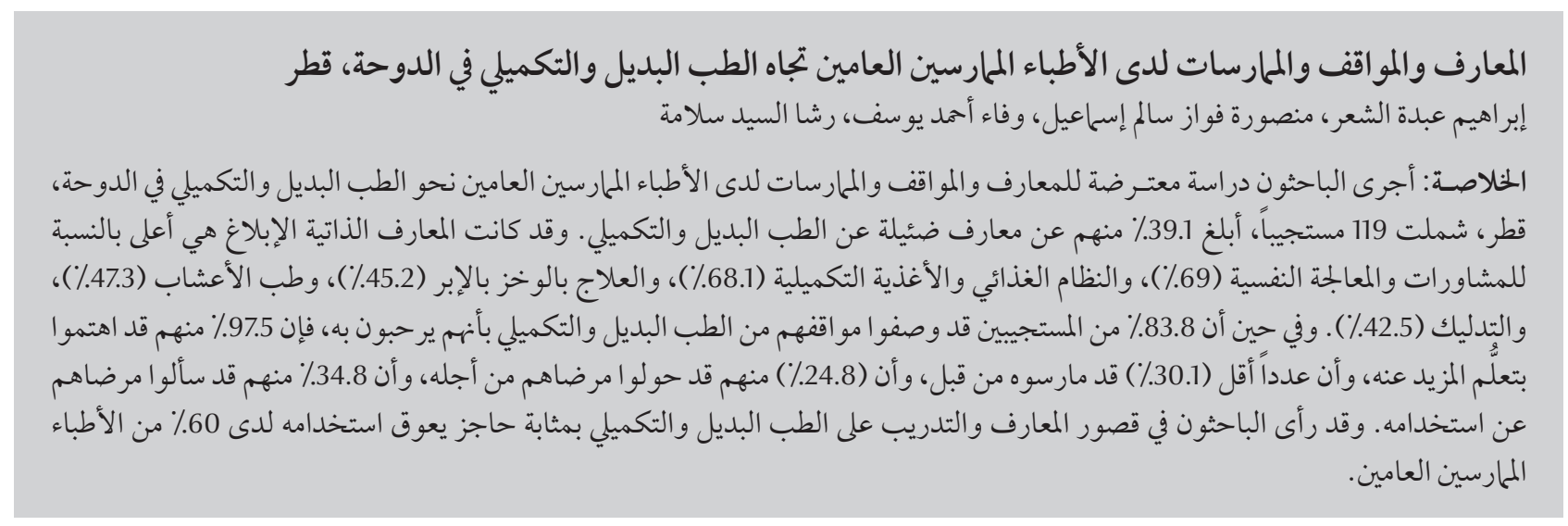

ABSTRACT A cross-sectional study of knowledge, attitudes and practice of general practitioners (GPs) towards complementary and alternative medicine (CAM) was conducted in Doha, Qatar. Out of 119 respondents, 39.1\% reported poor knowledge about CAM. Self-reported knowledge was highest for counselling and psychotherapy $(69.0 \%)$, diet and supplements (68.1\%), acupuncture $(45.2 \%)$, herbal medicine $(47.3 \%)$ and massage $(42.5 \%)$. While $83.8 \%$ described their attitude to CAM as welcoming and $97.5 \%$ were interested to learn more about it, fewer (30.1\%) had practised it before, referred patients (24.8\%) or asked patients' about their use of CAM (34.8\%). Their own lack of knowledge and training in CAM was seen as a barrier to its use by $60.0 \%$ of the GPs.

Connaissances, attitudes et pratique des médecins généralistes en matière de médecine complémentaire et alternative à Doha (Qatar)

RÉSUMÉ Une étude transversale des connaissances, des attitudes et de la pratique des médecins généralistes en matière de médecine complémentaire et alternative a été conduite à Doha, au Qatar. Parmi les 119 praticiens interrogés, 39,5\% d'entre eux ont déclaré qu'ils la connaissaient peu. Ils ont indiqué que leurs connaissances à ce sujet concernaient surtout le conseil et la psychothérapie (69,0\%), le régime et les suppléments alimentaires $(68,1 \%)$, l'acupuncture (45,2\%), les médicaments à base de plantes (47,3\%) et les massages (42,5\%). Alors que 83,8\% d'entre eux décrivent leur attitude vis-à-vis de la médecine complémentaire et alternative comme bienveillante, et que 97,5\% souhaiteraient la connaître davantage, peu de praticiens (30,1\%) I'ont déjà exercée. Ils étaient 24,8 \% à avoir orienté leurs patients vers des médecins la pratiquant, et 34,8 \% ont déjà interrogé leurs malades sur leur usage de la médecine complémentaire et alternative. Enfin, 60 \% d'entre eux considéraient leur manque de connaissances ou de formation dans ce domaine comme un obstacle à son utilisation.

'Department of Family Medicine, Hamad Medical Corporation, Doha, Qatar (Correspondence to M.F.S. Ismail: mansoura70@hotmail.com). ${ }^{2}$ Department of Family Medicine; ${ }^{3}$ Department of Community Medicine, Suez Canal University, Ismailia, Egypt.

Received: 25/05/08; accepted: 25/06/08 


\section{Introduction}

Complementary and alternative medicine (CAM) is defined by the National Center for Complementary and Alternative Medicine as "a group of diverse medical and health care systems, practices and products that are not presently considered to be part of conventional medicine" [1]. Despite uncertainties about the effectiveness of most CAM therapies, the use of CAM is growing in popularity among the public $[2,3]$ and studies suggest that $30 \%-98 \%$ of patients use some form of CAM therapy $[2,4,5]$. Dissatisfaction with mainstream modern medicine, particularly with regards to patientphysician relationships, concerns about the side-effects of chemical drugs and personal beliefs favouring a more holistic orientation to health care are often quoted as possible explanations $[3,6,7]$. As part of its global strategy for health for all, the World Health Organization has supported the integration of CAM into the mainstream medical system to improve the quality of care [8].

Estimates of the extent of use of CAM in industrialized countries range from about one-third to half of the general population $[9,10]$. Faced with the increasing demand for CAM by their patients, general practitioners (GPs) have to be prepared to discuss its uses and limitations, as well as its possible adverse effects [11]. They have to watch for signs of noncompliance with prescribed conventional treatments that may be associated with the use of CAM, as this is often not explicitly reported by patients [12].

Other studies have described GPs' views [13] and practices [14] about CAM. However, such studies are often hampered by methodological problems such as small sample sizes, convenience sampling or unsatisfactory response rates [2]. A study in Saudi Arabia showed that $23.9 \%$ of primary health care patients reported previous use of traditional remedies [15]. More data about CAM is needed from countries of the Eastern Mediterranean region. This paper reports the results of a crosssectional study in Qatar with the aim of exploring GPs' knowledge, attitude and practice regarding CAM.

\section{Methods}

This was a cross-sectional study conducted during the period April 2007 to March 2008 to assess knowledge, attitude and practice towards CAM of GPs working in primary care in Doha.

\section{Study population}

The total number of primary care GPs working in Qatar at the time of the study was 277 and all 170 GPs working in the capital city, Doha, were included in the survey.

\section{Data collection}

A structured self-administered questionnaire was used for data collection. The questionnaire was sent by mail to all participants. Follow-up by postal reminders, phone calls and personal visits were made in order to reduce the non-response rate.

The questionnaire was specially designed for the study and consisted of 4 sections. The first section included demographic data: sex, age, nationality, postgraduate qualification, job description, and length of practice. The second section included questions about GPs' self-reported knowledge of CAM. Respondents indicated their knowledge about 9 CAM therapies, chosen for this survey based on earlier surveys conducted in the United States of America and some European and Arab countries, in order to represent each of the main categories of CAM. Respondents were required to choose 1 of 3 possible responses for each therapy (excellent to good, poor or don't know). The third section included questions about the attitudes of physicians towards CAM. GPs were also asked their opinions of 11 items about CAM therapy and responses were ranked on a 4-point scale (strongly agree, agree, disagree or strongly disagree). The last section was questions about whether they had used CAM before, if they had ever taken a history of patients' use of CAM or ever referred patient to a CAM practitioner before. The questionnaire also enquired about GPs' interest in CAM and if they had received any previous training in CAM.

The research was approved by the Qatar national ethical committee. Informed consent was signed by participants after an explanation of the purpose of the study, the direct and indirect benefits and risks as well as the confidentiality of collected data with their right to withdraw at any stage of the study.

\section{Data analysis}

The collected data were analysed using SPSS, version 9. For cross-tabulation and computation, statistical significance using $95 \%$ confidence interval (CI) was calculated. The chi-squared test was used for the comparison of different categorical groups with a $P$-value $<0.05$ considered to be statistically significant.

\section{Results}

Of the 170 questionnaires distributed, 119 questionnaires were returned with complete information, a response rate of $70 \%$. Of the respondents 59 (49.6\%) were males and $60(50.4 \%)$ were females. The mean age was 44 (standard deviation 12) years. Only $29.4 \%$ of the respondents were of Qatari nationality. One-quarter of the GPs $(31,26.1 \%)$ had a postgraduate qualification in family and community medicine and 61 had more than 8 years experience as primary care GPs. A majority of the respondents were clinical associates $(42.5 \%)$ or residents (36.3\%) (Table 1).

More than one-third of the GPs (39.1\%) stated that their knowledge about CAM therapy was poor, while $54.8 \%$ described it as good and only $6.1 \%$ classified their knowledge about 


\begin{tabular}{|c|c|c|}
\hline \multicolumn{3}{|c|}{$\begin{array}{l}\text { Table } 1 \text { Demographic characteristics of } \\
\text { the studied general practitioners (GPs) } \\
\text { in Doha }(n=119)\end{array}$} \\
\hline Characteristic & No. ${ }^{a}$ & $\%$ \\
\hline \multicolumn{3}{|l|}{ Age (years) } \\
\hline$<40$ & 61 & 51.3 \\
\hline$\geq 40$ & 58 & 48.7 \\
\hline \multicolumn{3}{|l|}{ Sex } \\
\hline Male & 59 & 49.6 \\
\hline Female & 60 & 50.4 \\
\hline \multicolumn{3}{|l|}{ Nationality } \\
\hline Qatari & 35 & 29.4 \\
\hline Non-Qatari & 84 & 70.6 \\
\hline \multicolumn{3}{|l|}{ Qualifications $^{b}$} \\
\hline Family medicine & 31 & 26.1 \\
\hline $\mathrm{MB} B C h$ & 43 & 36.1 \\
\hline Other & 45 & 37.8 \\
\hline \multicolumn{3}{|l|}{ Job description } \\
\hline Consultant & 7 & 6.2 \\
\hline Clinical associate & 48 & 42.5 \\
\hline Resident & 41 & 36.3 \\
\hline Specialist & 17 & 15.0 \\
\hline \multicolumn{3}{|l|}{$\begin{array}{l}\text { Experience as a } \\
\text { GP(years) }\end{array}$} \\
\hline$<4$ & 25 & 21.0 \\
\hline $4-8$ & 33 & 27.7 \\
\hline$>8$ & 61 & 51.3 \\
\hline
\end{tabular}

${ }^{a}$ Data were missing in some categories.

${ }^{b}$ Family and Community Medicine qualification.

CAM as excellent. Learning about CAM as part of medical education was the most common source of knowledge (60.0\%), followed by medical journals (29.1\%) (Table 2). GPs' self-reported knowledge about specific CAM therapies was highest for the following: counselling and psychotherapy (69.0\%), diet and supplements (68.1\%), acupuncture (45.2\%), herbal medicine (47.3\%) and massage (42.5\%) (Table 3).

The great majority of the GPs (83.8\%) described their own attitude towards CAM as welcoming and $97.5 \%$ were interested in learning more about CAM therapy (Table 4). The majority of the GPs (93.1\%) had not received any previous training in CAM. However, most of them (90.7\%) showed an interest in attending future courses in CAM. Almost $70 \%$ of the GPs were interested in knowing more about the mechanisms

\begin{tabular}{lc}
\hline Table 2 Self-reported level of knowledge of general practitioners in Doha about \\
complementary and alternative medicine (CAM) $(\boldsymbol{n}=119)$ \\
\hline Item & $\%$ \\
Level of knowledge about CAM & 6.1 \\
$\quad$ Excellent & 54.8 \\
Good & 39.1 \\
Poor & \\
Main source of knowledge about CAM & 60.0 \\
As part of medical education & 29.1 \\
Medical journals & 10.9 \\
Other &
\end{tabular}

of action of CAM. However, 59.8\% believed that certain types of CAM were beneficial; while only $4.3 \%$ believed they were not beneficial at all (Table 4).

The majority of the GPs (82.7\%) favoured CAM as a useful supplement to conventional medicine and described it as having beneficial ideas and methods for physicians (93.5\%). Most of the respondents (83.2\%) agreed that CAM should be practised in Qatar (Table 5). Some, however, believed that CAM worked only with the placebo effect (25.0\%) and $30.9 \%$ believed that it was a threat to public health. Almost all (96.5\%) agreed that CAM practitioners should be fully qualified and licensed by law.

More than two-thirds of the GPs (69.9\%) had not used CAM therapies before with their patients but $24.8 \%$ had referred their patients to a CAM practitioner. Around one-third of the

GPs (34.8\%) reported that they asked about patients' history of CAM use, $50.4 \%$ sometimes asked, while only $14.8 \%$ did not ask at all (Table 6). Around half of the GPs (50.9\%) had personal experience of the use of CAM. The common constraints facing their own use of CAM, mentioned by $60.0 \%$ of GPs, were lack of training and knowledge. There was a statistically significant relationship between GPs' previous training and their practice of referring patients for CAM $(P<0.05)$ (Table $7)$; other demographic factors had no significant effect on willingness to refer patients (data not shown).

\section{Discussion}

It seems clear that CAM will be a part of health care for much of the population

\begin{tabular}{|c|c|c|c|}
\hline \multirow{3}{*}{ Type of CAM } & \multicolumn{3}{|c|}{ Level of knowledge } \\
\hline & Excellent/Good & Poor & Don't know \\
\hline & $\%$ & $\%$ & $\%$ \\
\hline Counselling \& psychotherapy & 69.0 & 21.2 & 9.8 \\
\hline Diet/supplements & 68.1 & 24.1 & 7.8 \\
\hline Herbal medicine & 47.3 & 42.9 & 9.8 \\
\hline Acupuncture & 45.1 & 45.4 & 9.5 \\
\hline Massage & 42.5 & 46.0 & 11.5 \\
\hline Homeopathy & 21.8 & 45.5 & 32.7 \\
\hline Faith healing & 20.6 & 44.9 & 34.6 \\
\hline Chiropractic & 18.0 & 45.9 & 36.0 \\
\hline Naturopathy & 9.3 & 45.4 & 45.4 \\
\hline Other & 18.2 & 31.8 & 50.0 \\
\hline
\end{tabular}




\begin{tabular}{|c|c|}
\hline Item & $\%$ \\
\hline \multicolumn{2}{|l|}{ Attitude to CAM } \\
\hline Extremely welcoming & 11.1 \\
\hline Welcoming & 83.8 \\
\hline Not welcoming & 5.1 \\
\hline \multicolumn{2}{|l|}{ Interested in CAM } \\
\hline Yes & 97.5 \\
\hline No & 2.5 \\
\hline \multicolumn{2}{|l|}{ Have previous training in CAM } \\
\hline Yes & 6.9 \\
\hline No & 93.1 \\
\hline \multicolumn{2}{|l|}{ Training affects a doctor's practice } \\
\hline Yes & 34.8 \\
\hline No & 65.2 \\
\hline \multicolumn{2}{|l|}{ Interested in attending future courses in CAM } \\
\hline Yes & 90.7 \\
\hline No & 9.3 \\
\hline \multicolumn{2}{|l|}{ Agree CAM is beneficial } \\
\hline Yes & 35.9 \\
\hline No & 4.3 \\
\hline Certain types & 59.8 \\
\hline \multicolumn{2}{|l|}{ Areas of CAM would like to know more about: } \\
\hline Mechanism of action & 69.8 \\
\hline Side-effects and safety & 21.6 \\
\hline Cost-effectiveness & 2.6 \\
\hline Optimal combination with conventional therapy & 6.0 \\
\hline
\end{tabular}

\begin{tabular}{|c|c|c|}
\hline $\begin{array}{l}\text { Table } 5 \text { Beliefs of general practitioners in Doha about } \\
\text { alternative medicine (CAM) therapies }(n=119)\end{array}$ & omplemer & and \\
\hline Item & $\begin{array}{c}\text { Strongly } \\
\text { agree/ } \\
\text { agree }\end{array}$ & $\begin{array}{c}\text { Strongly } \\
\text { disagree/ } \\
\text { disagree }\end{array}$ \\
\hline & $\%$ & $\%$ \\
\hline CAM should be regulated by law & 89.4 & 10.6 \\
\hline CAM should be practised in Qatar & 83.2 & 16.8 \\
\hline $\begin{array}{l}\text { CAM should be included in undergraduate medical } \\
\text { education curriculum }\end{array}$ & 80.7 & 19.3 \\
\hline There is a need for physician supervision of CAM & 91.9 & 8.2 \\
\hline There is a scientific basis for CAM & 86.6 & 13.4 \\
\hline CAM results are usually due to the placebo effect & 25.0 & 75.0 \\
\hline CAM is a threat to the public's health & 30.9 & 69.1 \\
\hline $\begin{array}{l}\text { CAM practitioners should be fully qualified and } \\
\text { licensed by law }\end{array}$ & 96.5 & 3.5 \\
\hline $\begin{array}{l}\text { CAM includes ideas and methods that physicians } \\
\text { could benefit from }\end{array}$ & 93.5 & 6.5 \\
\hline $\begin{array}{l}\text { Treatments not tested in a scientifically recognized } \\
\text { manner should be discouraged }\end{array}$ & 88.5 & 11.5 \\
\hline CAM is a useful supplement to conventional medicine & 82.7 & 17.3 \\
\hline
\end{tabular}

for the foreseeable future. Fortunately, the research base in this realm has been growingrapidly $[8,16]$.Ahigh proportion of the GPs in our study in Qatar (39.1\%) perceived their knowledge about CAM to be poor. This is not surprising given that many of the respondents went their through medical training when CAM was not widely discussed.

Of the various CAM therapies, GPs reported more knowledge about psychotherapy and counselling, diet and supplements, acupuncture and massage. Different results were found in a study conducted in the United Arab Emirates (UAE), which showed that GPs were more aware about and supportive of herbal medicine, acupuncture and homeopathy [17]. Ernest et al. in their global meta-analysis, found that manipulative therapies such as chiropractic and osteopathy, acupuncture and homeopathy (in that order) were believed by physicians to be the most useful or effective forms of CAM therapy [13].

The attitude of GPs in our study appears to be supportive of CAM, as the majority agreed that it was a useful supplement to conventional medicine and it included ideas and methods that could be of benefit to the primary care physician. They also supported and recommended that the practise of CAM in Qatar be by qualified practitioners who were licensed by law and they favoured some sort of legal supervision. Similar opinions and attitudes were found among Canadian physicians [18]. Most of our participants had no previous training in CAM; however, $97.5 \%$ showed a great interest in attending courses in CAM. Canadian and Australian GPs reported a higher level of training than our GPs but only $50 \%$ of those without training were found to be interested in learning about CAM $[18,19]$.

Only one-third of the GPs had used CAM before with their patients; there was also a low referral rate to CAM practitioners. This may be attributed to the absence of specific CAM centres in Qatar and the lack of knowledge and 


\begin{tabular}{lc}
\hline Table 6 Practice of complementary and alternative medicine (CAM) by general \\
practitioners in Doha $(\boldsymbol{n}=\mathbf{1 1 9})$ \\
\hline Item & $\%$ \\
\hline During practice as GP: & 30.1 \\
Have used CAM with patients & 26.5 \\
Considered use of CAM with patients & 43.4 \\
Have not used CAM & \\
Have referred patients to CAM practitioner & 24.8 \\
Yes & 75.2 \\
No & \\
Have asked patients about their use of CAM & 34.8 \\
Yes & 14.8 \\
No & 50.4 \\
Sometimes & \\
Have personal experience of CAM & 50.9 \\
Yes & 49.1 \\
No & \\
Most common constraint facing own use of CAM & 60.0 \\
Lack of knowledge and training & 18.0 \\
Lack of studies supporting CAM & 12.0 \\
Licence by health authority & 10.0 \\
Cost & \\
\hline
\end{tabular}

training of physicians in CAM. This contrasts with the results of a study in UAE showing that $32 \%$ of GPs referred their patients to herbal medicine specialties, indicating the popularity of herbal medicine in the Emirates [17]. On the other hand, 20\% of GPs in Victoria, Australia, practised CAM; 93\% had referred their patients at least once and $82 \%$ a few times a year for CAM therapy [19].
Previous studies have shown that certain demographic factors such as age, sex, ethnicity, practice type and location of medical training have a significant effect on physicians' attitudes [20]. Contrary to these studies, our study showed only a statistically significant relationship between GPs' previous training and their practice or referral pattern of CAM.

\begin{tabular}{|c|c|c|c|}
\hline \multicolumn{4}{|c|}{$\begin{array}{l}\text { Table } 7 \text { Referral of patients to complementary and alternative medicine (CAM) of } \\
\text { general practitioners in Doha by previous training }\end{array}$} \\
\hline Item & $\begin{array}{l}\text { Previous } \\
\text { training in } \\
\text { CAM }(n=8)\end{array}$ & $\begin{array}{l}\text { No previous } \\
\text { training in } \\
\text { CAM }(n=111)\end{array}$ & $x^{2}(P$-value $)$ \\
\hline & $\%$ & $\%$ & \\
\hline Use of CAM & & & $6.384(0.041)$ \\
\hline Have used CAM with patients & 75.0 & 27.9 & \\
\hline Considered using CAM with patients & 0.0 & 27.9 & \\
\hline Have not used CAM & 25.0 & 44.2 & \\
\hline $\begin{array}{l}\text { Have referred patients to } C A M \\
\text { practitioner }\end{array}$ & & & $6.351(0.024)$ \\
\hline Yes & 62.5 & 22.5 & \\
\hline No & 37.5 & 77.5 & \\
\hline
\end{tabular}

The variations between countries regarding the familiarity of GPs with different CAM therapies, their attitude, practice pattern and referral rates can be explained by cultural and geographical differences and beliefs. Such differences, however, are considerable and indicate the need for regional studies before designing educational programmes or making decisions about any reforms to health care systems.

Our study had several limitations. First, the response rate was lower than desired. In reviewing the literature, similar physician surveys have yielded response rates between $17.5 \%$ [21] and $72 \%$ [22]. Thus, the results should be interpreted with caution because those with strong feelings towards CAM (for or against) may have been more likely to respond to the survey. The survey only included primary care physicians. Attitudes and knowledge about CAM could be considerably different in physicians at different levels and specialties of health care. Thus, it would be interesting to compare attitudes and knowledge across such varied practice settings.

\section{Conclusions}

The results of our study show that although many physicians were interested in helping their patients to make use of CAM, most did not feel qualified to do so. It suggests that knowledge about CAM among GPs in Qatar is not as widespread as the public demand seems to require. Clearly physicians need evidence-based and readily available training and resources about CAM..

\section{Acknowledgements}

We wish to thank Qatar GPs for their collaboration and the research committee in Hamad Medical Corporation, which had a big role in the study design, data collection, data analysis, data interpretation and writing of the report. 


\section{References}

1. What is complementary and alternative medicine (CAM)? Bethesda, Maryland, National Center for Complementary and Alternative Medicine, 2005 (Publication No. D156).

2. Eisenberg DM et al. Trends in alternative medicine use in the United States, 1990-1997. Results of a follow-up national survey. Journal of the American Medical Association, 1998, 280:1569-75.

3. WHO traditional medicine strategy 2002-2005. Geneva, World Health Organization, 2002.

4. Wahner-Roedler DL et al. Complementary and alternative medicine: use by patients seen in different specialty areas in a tertiary-care centre. Evidence-based integrative medicine, 2004, 1:253-60.

5. Goldstein MS et al. The use of complementary and alternative medicine among California adults with and without cancer. Evidence-based complementary and alternative medicine, 2005, 2:557-65.

6. Astin JA. Why patients use alternative medicine: results of a national study. Journal of the American Medical Association, 1998, 279:1548-53.

7. Coulter ID, Willis EM. The rise and rise of complementary and alternative medicine: a sociological perspective. Medical journal of Australia, 2004, 180:587-9.

8. Lewith $\mathrm{G}$ et al. Developing CAM research capacity for complementary medicine. Evidence-based complementary and alternative medicine, 2006, 3:283-9.

9. Ernst E. The role of complementary and alternative medicine. British medical journal, 2000, 321:1133-5.

10. Bodeker G, Kronenberg F. A public health agenda for traditional, complementary, and alternative medicine. American journal of public health, 2002, 92:1582-91.

11. Jonas WB. Alternative medicine and the family physician. Journal of the American Board of Family Practice, 1998, 11:244-6.

12. Zollman C, Vickers A. ABC of complementary medicine: complementary medicine and the doctor. British medical journal, 1999, 319:1558-61.
13. Ernst E, Resch KL, White AR. Complementary medicine. What physicians think of it: a meta-analysis. Archives of internal medicine, 1995, 155:2405-8.

14. Pirotta $\mathrm{M}$ et al. Characteristics of Victorian general practitioners who practice complementary therapies. Australian family physician, 2002, 31:1133-8.

15. Al-Najjar N, Taha AZ, Alubier AG. Prevalence of utilizing native medicine among primary care consumers. Saudi medical journal, 1998, 19(5):551-4.

16. Lewith G. Complementary medicine research unit. Evidencebased complementary and alternative medicine, 2005, 2:399407.

17. Hassan MY, Das M, Behjat S. Alternative medicine and the medical profession: views of medical students and general practitioners. Eastern Mediterranean health journal, 2000, 6(1):25-33 (http://www.emro.who.int/publications/emhj/0601/03. htm).

18. Verhoef MJ, Sutherland LR. Alternative medicine and general practitioners: opinions and behavior. Canadian family physician, 1995, 41:1005-11.

19. Pirotta MV et al. Complementary therapy: have they become accepted in general practice? Medical journal of Australia, 2000, 172(3):105-9.

20. Gordon D et al. Complementary and alternative medicine: Canadian psychiatrists' attitudes and behavior. Archives of physical medicine and rehabilitation, 2000, 81(5):662-7.

21. Chan PS, Wong MM. Physicians and complementary-alternative medicine: training, attitudes, and practices in Hawaii. Hawaii medical journal, 2004, 63:176-81.

22. Levine SM, Weber-Levine ML, Mayberry RM. Complementary and alternative medical practices: training, experience, and attitudes of a primary care medical school faculty. Journal of the American Board of Family Practice, 2003, 16:318-26. 